\title{
Assessment of Risk due to Debris Flow Events: A Case Study in Central Taiwan
}

\author{
GWO-FONG LIN ${ }^{1, \star}$, LU-HSIEN CHEN ${ }^{2}$ and JUN-NAN LAI ${ }^{1}$ \\ ${ }^{1}$ Department of Civil Engineering, National Taiwan University, Taipei 10617, Taiwan; \\ ${ }^{2}$ Department of Information Management, Diwan College of Management, Madou, Tainan \\ 72141, Taiwan
}

(Received: 30 December 2003; accepted: 9 August 2005)

\begin{abstract}
In this paper, based on the concepts of uncertainty and reliability analyses, a method used for assessment of risk due to debris flow events is proposed. First, procedures for obtaining the configuration of debris-flow fans are presented. Then, the parameters affecting the configuration of debris-flow fans are identified and their corresponding means and standard deviations are derived. Finally, the proposed method is applied to the Shih-Pa-Chung Creek in central Taiwan. The expected deposition thickness at any point in the deposition area is computed and then the contours of risk for the 50-year and 100-year events are constructed. Regarding the expected deposition thickness, it is found that the closer the distance from the canyon mouth, the larger the debris-flow thickness becomes. The results also show that the contours of risk are of the shape of an ellipse similar to the shape of deposition area, and the risk at a point decreases with increasing distance of that point from the canyon mouth. In addition, when the return period of rainfall event is fixed, the variation in risk decreases as the distance from the canyon mouth increases. For the assessment of risk due to debris flow events, the proposed method is recommended as an alternative to the existing methods, because the influence of all the uncertainty of the parameters is considered.
\end{abstract}

Key words: risk assessment, debris flow, deposition area, reliability, uncertainty

\section{Introduction}

Debris flows, which are sometimes referred as mudslides, mudflows, lahars, or debris avalanches, are common types of fast-moving landslides. These flows generally occur during periods of intense rainfall or rapid snowmelt. They usually start on steep hillsides as shallow landslides. Initiation of debris flows requires loose rock and soil deposits, steep slop, and free flowing water from snowmelt or a rainstorm. Debris flows from many different sources can combine in channels where their destructive power may be greatly increased. They continue flowing down hills and through channels, growing in volume with the addition of water, sand,

\footnotetext{
^ Author for correspondence: E-mail: gflin@ntu.edu.tw
} 
boulders, trees, and other materials. When the flows reach canyon mouths or flatter ground, the debris spreads over a broad area and the debris-flow fan forms.

Taiwan is a mountainous island where two-thirds of area located in mountainous zones. Unfortunately, its geological condition is weak, and hence during heavy rainfalls, the colluvium is easily weakened, which often leads to a debris flow. Many severe debris flows have happened in Taiwan (Hung, 1996; Cheng et al., 1997, 2000). For example, the 1990 Tong-Mang Valley event (located in eastern Taiwan) that claimed 35 lives, and the 1996 Chen-Yu-Lan River event (located in central Taiwan) that claimed 18 lives. The debris flows often cause serious loss. Therefore, how to reduce the debris-flow hazards becomes the most important task in Taiwan. The processes of debris flows are complex and reliable modification of it requires a degree of understanding. An easy method to reduce debris flow disasters is to remove people and their assets from areas likely to be affected by debris flows (Davies, 1997). Unfortunately, this is impossible owing to the limited space, as well as social and legal difficulties. On the other hand, a real-time prediction and warning system is helpful (Sorensen, 2000). However, it is inevitable that people face debris flow disasters. The assessment of risk due to debris flow events prior to actual disasters, therefore, becomes an effective method to reduce the debris-flow hazards.

Before assessing debris-flow hazard, one should first know the configuration of debris-flow fan. That is, one should know how long, how wide and how thick the debris flow can deposit, as well as how much volume and in what zones the debris flow deposits. The process of formation and the shape of debris-flow fan have drawn attention of many researchers such as Takahashi (1991), Hungr (1995), Iverson (1997), Shih et al. (1997), Fannin and Wise (2001), and Wilkerson and Schmid (2003). Takahashi (1991) proposed empirical formulas for the probable maximum length and thickness of the debris-flow deposits. Major and Pierson (1992) made experimental analysis of fine-grained slurries. Shieh and Tsai (1997) constructed the relationships among the maximum length, width and thickness based on the experimental data. Shih et al. (1997) studied the grading of risk for hazardous debris-flow zones. Lin et al. (2002) applied geographic information system (GIS) techniques for assessing debris-flow hazards. Clague et al. (2003) used the peak discharge as input into an empirical equation to estimate the volume of debris flows. D'Ambrosio et al. (2003) presented a cellular automata model for simulating debris-flow phenomena. Liu and Lei (2003) presented a new method that can estimate debris flow hazard from gully density, mean annual rainfall and percentage of cultivated land on steep slope.

So far, the delineation of the debris-flow deposition area is limited to a deterministic approach. That is, existing methods ignore the influence of 
the parameters on the probable maximum length, width and thickness. However, the influence factors of debris-flow deposition are numerous and the empirical, self-empirical or theoretical models that have been developed are too simple. To build a complete and reasonable model for delineating debris-flow hazards is not easy. Hence, uncertainty and reliability analyses (Yen and Tung, 1993) should be used. Reliability analysis is increasingly used in applications of hydraulic and hydrologic engineering, such as groundwater (Hamed et al., 1996), debris flows (Archetti and Lamberti, 2003; Lin et al., 2004), water resource management (Yen and Tung, 1993), watershed water quality model (Bobba et al., 1996), and selective index for regional flood frequency analysis (Lin and Chen, 2003).

There are two objectives in this paper. One is to find the expected 3-D distribution of the debris flow and the other is to compute the risk based on the concepts of uncertainty and reliability analyses. We define 'risk' as the probability that the thickness of the deposition area is larger than a certain height herein. First, the configuration of debris-flow fan is introduced. Furthermore, the mean and variance of thickness at any point are derived. Finally, the actual application is performed. The expected deposition thickness at any point in the deposition area is computed and the contours of risk are constructed.

\section{Configuration of Debris-Flow Fan}

To compute the configuration of debris-flow fan, the maximum deposition length, width and thickness need to be known. Procedures for obtaining the configuration of debris-flow fan are presented as below. Following the experiments of Shieh and Tsai (1997), let $x$ is the distance from the canyon mouth, and then the thickness $Z_{\mathrm{c}}$ (see Figure 1) in the primary debris-flow direction, which varies with $x$, can be described by

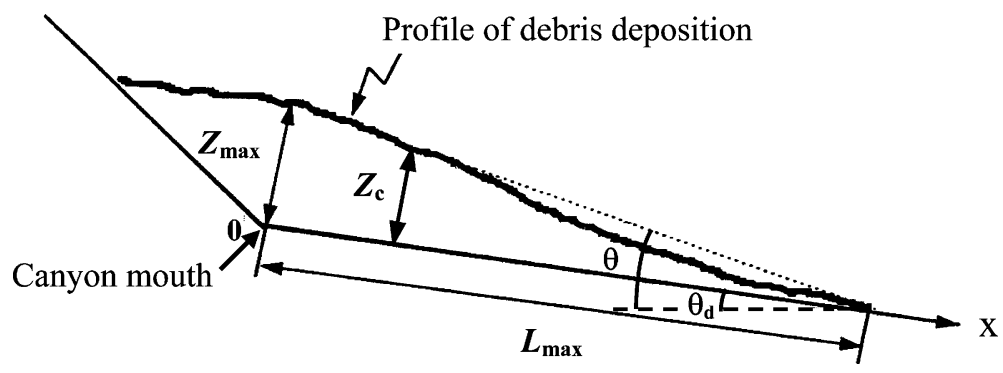

Figure 1. A sketch of a debris-flow longitudinal profile. 


$$
Z_{\mathrm{c}}=Z_{\max } \exp \left[-\frac{1}{2 C_{\mathrm{L}}^{2}}\left(\frac{x}{L_{\max }}\right)^{2}\right]
$$

where $Z_{\max }$ is the maximum deposition thickness that is at $x=0$ (Figure 1), $L_{\max }$ is the maximum deposition length, and $C_{\mathrm{L}}$ is a coefficient varying from 0.39 to 0.40 . As to the estimation of $L_{\max }$, the formula proposed by Takahashi (1991) has been widely used (see Appendix A). At any point ( $x$, $y$ ), the deposition thickness can be written as

$$
Z_{x y}=Z_{\mathrm{c}} \exp \left[-\frac{1}{2 C_{\mathrm{B}}^{2}}\left(\frac{y}{b}\right)^{2}\right]
$$

where $b$ is the deposition width at $x$ (see Figure 2) and $C_{\mathrm{B}}$ is a coefficient varying from 0.20 to 0.21 . The $Z_{\max }$ in Equation (1) and $b$ in Equation (2) can be obtained as follows. According to Figure 1, the maximum deposition thickness $Z_{\max }$ can be written as

$$
Z_{\max }=L_{\max } \tan \left(\theta-\theta_{\mathrm{d}}\right)
$$

where $\theta$ is the longitudinal slope of debris-flow deposits (degree) and $\theta_{\mathrm{d}}$ is the bed slope of debris-flow fan downstream of the end of the flow channel (degree).

According to the experimental results of Shieh and Tsai (1997), the shape of the deposition area (Figure 2) can be described by

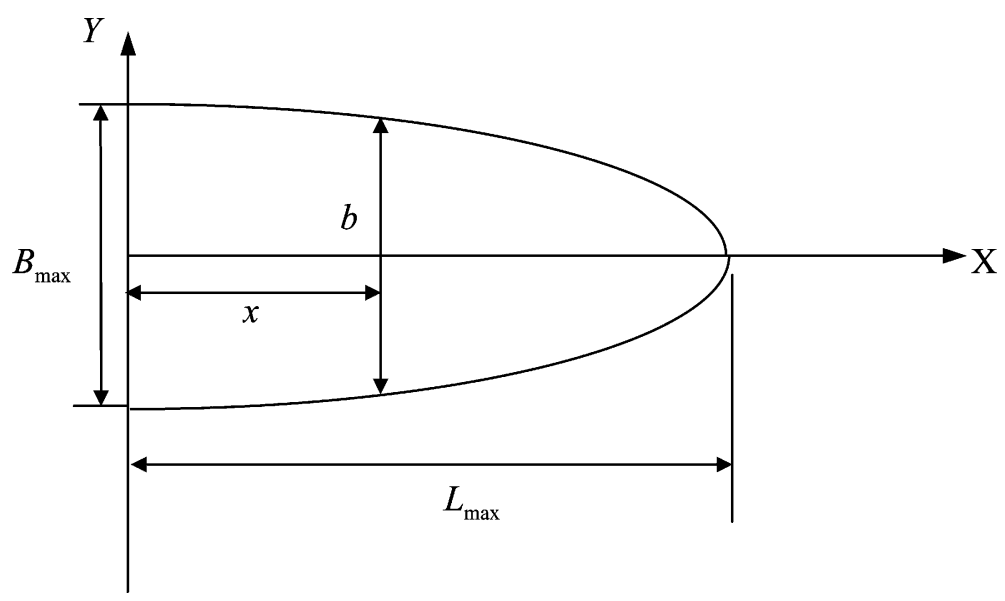

Figure 2. The top view of the deposition area. 


$$
\left(\frac{b}{B_{\max }}\right)^{2}+\left(\frac{x}{L_{\max }}\right)^{2}=1, \quad 0 \leq x \leq L_{\max }
$$

where $B_{\max }$ is the maximum deposition width, and $x, b$ and $L_{\max }$ are as defined earlier. According to Equation (4), the width at any distance $x$ from the canyon mouth is

$$
b=B_{\max }\left[1-\left(\frac{x}{L_{\max }}\right)^{2}\right]^{0.5}
$$

\section{Assessment of Risk due to Debris Flow Events}

The methodology used for assessment of risk due to debris flow events is briefly presented in this section. When performing an assessment of risk due to debris flow events, one expects to know the risk, i.e. the probability that the thickness at any point of the deposition area is more than a certain height. The probability that the thickness $Z_{x y}$ exceeds a certain height $Z^{*}$ is referred to as risk $r^{\prime}$ :

$$
r^{\prime}=\operatorname{Prob}\left[Z^{*} \leq Z_{x y}\right]=\operatorname{Prob}[\mathrm{SM} \leq 0]
$$

where safety margin $\mathrm{SM}=Z^{*}-Z_{x y}$. Equation (6) can be further written as

$$
r^{\prime}=\operatorname{Prob}\left[U \leq-\left(\mu_{\mathrm{SM}} / \sigma_{\mathrm{SM}}\right)\right]=1-F_{U}\left(\mu_{\mathrm{SM}} / \sigma_{\mathrm{SM}}\right)
$$

where $U=\left(\mathrm{SM}-\mu_{\mathrm{SM}}\right) / \sigma_{\mathrm{SM}}$ is the standardized normal random variable, $F_{U}(u)$ is the cumulative distribution function of the standardized random variable $U$, and $\mu_{\mathrm{SM}}$ and $\sigma_{\mathrm{SM}}$ are the mean and the standard deviation of $\mathrm{SM}$, respectively. The $\mu_{\mathrm{SM}}$ can be obtained from

$$
\mu_{\mathrm{SM}}=E\left[Z^{*}-Z_{x y}\right]=\mu_{Z^{*}}-\mu_{Z_{x y}}
$$

where $E$ is the expectation operator, and $\mu_{Z^{*}}$ and $\mu_{Z_{x y}}$ are the means of $Z^{*}$ and $Z_{x y}$, respectively. When $Z^{*}$ and $Z_{x y}$ are independent, $\sigma_{\mathrm{SM}}^{2}$ is given by

$$
\sigma_{\mathrm{SM}}^{2}=\sigma_{Z^{*}}^{2}+\sigma_{Z_{x y}}^{2}
$$

where $\sigma_{Z^{*}}^{2}$ and $\sigma_{Z_{x y}}^{2}$ are respectively the variance of $Z^{*}$ and $Z_{x y}$. In this paper, $Z^{*}$ is set equal to a certain height, i.e. $Z^{*}$ is deterministic. Thus we need to know $\mu_{Z_{x y}}$ and $\sigma_{Z_{x y}}^{2}$ to calculate $\mu_{\mathrm{SM}}$ and $\sigma_{\mathrm{SM}}^{2}$ according to Equations (8) and (9). Once $\mu_{Z_{x y}}$ and $\sigma_{Z_{x y}}^{2}$ are obtained, $r^{\prime}$ can be computed from Equation (7). In Appendix $\mathrm{B}$, the mean and variance of $Z_{x y}$ are derived. 


\section{Application and Discussions}

The Shih-Pa-Chung Creek susceptible to debris-flows in central Taiwan is chosen as the study area in this paper. Figure 3 shows the study area and the location of the Wan-Hsiang rain gauge. This creek is a tributary of the Chen-Yu-Lan River that flows into the Chou-Shui River, the longest river in Taiwan. The Shih-Pa-Chung Creek is incised along the Ti-Li Fault and close to the Chen-Yu-Lan Fault, so that the geology and topography create a environment prone to debris flows. In the recent years, three major debris flows occurred in this study area in 1986, 1987, 1996 (Cheng et al., 2000). Therefore, the Council of Agriculture (1996) classified the Shih-PaChung Creek as a hazardous debris-flow stream.

In this application, at first we need to estimate the means and variances of the upstream and downstream bed slopes of the debris-flow path, drainage area, the length of overland flow path, the length of channel, and the elevation difference between the inlet and outlet of the main channel. In this application, based on the topographic map with a scale of 1:10,000, well-trained persons are asked to measure these variables. For each random variable, a set of readings from different persons is then formed from which the mean and variance can be estimated. Table I presents the means and standard deviations of the aforementioned geometric variables, and Table II presents the means and standard

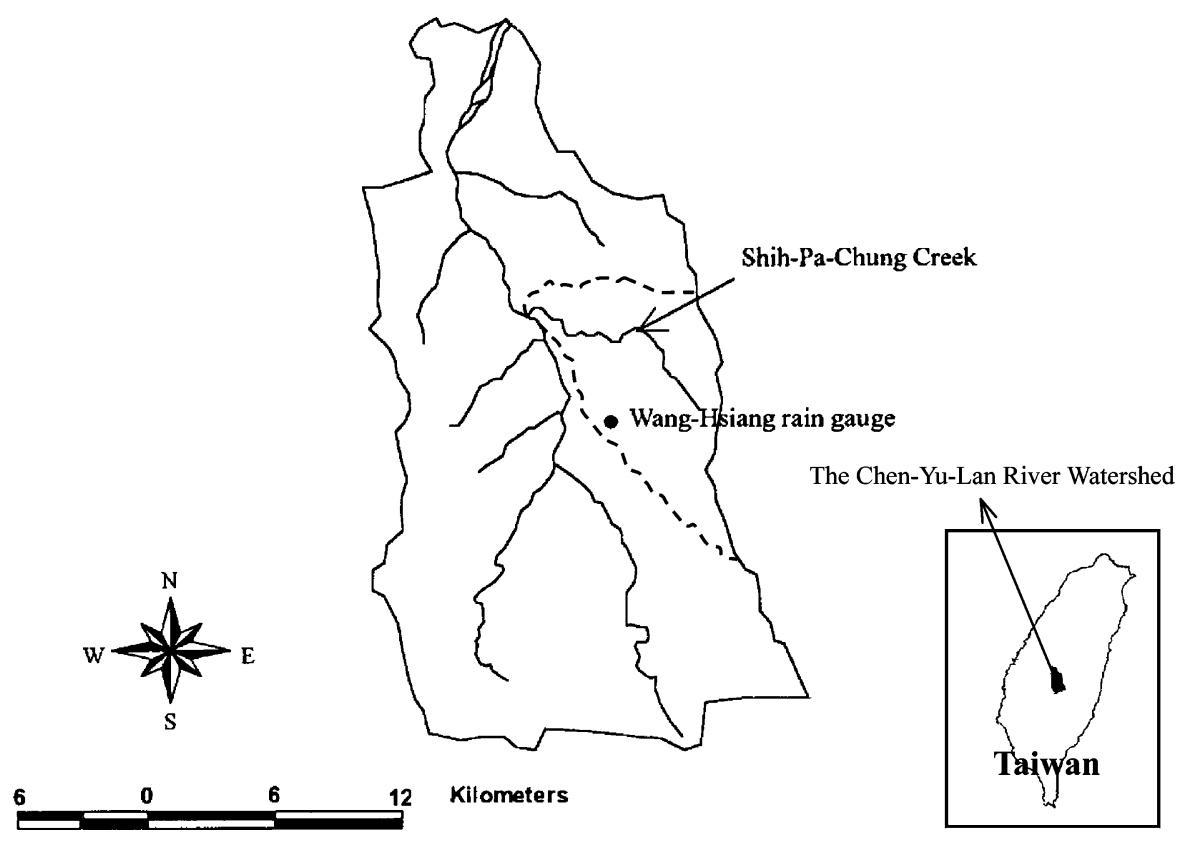

Figure 3. The Chen-Yu-Lan River Watershed in central Taiwan. 
deviations of the hydrologic variables and the debris-flow variables for two different return periods (50 and 100 years). The variables in Table II are estimated using the formulas in the literature. One can refer to Lin et al. (2004) for the details of the formulas. The key factor in the estimation of the variables is rainfall intensity. As to rainfall, in total we use 43 annual rainfall observations (1960-2002) to find the 50- and 100-year design rainfall intensities. In addition, Table III summarizes the means

Table I. Means and standard deviations of geometric variables.

\begin{tabular}{lrc}
\hline Variable & Mean & Standard deviation \\
\hline Bed slope of canyon $\theta_{\mathrm{u}}$ (degree) & 14.0 & 3.5 \\
Drainage area $A$ (ha) & 210.0 & 10.5 \\
\hline
\end{tabular}

Table II. Means and standard deviations of the hydrologic variables and the debris-flow variables for two different return periods.

\begin{tabular}{|c|c|c|c|c|}
\hline \multirow[t]{3}{*}{ Variable } & \multicolumn{4}{|c|}{ Return period $T$ (years) } \\
\hline & \multicolumn{2}{|l|}{50} & \multicolumn{2}{|l|}{100} \\
\hline & Mean & Std. dev. & Mean & Std. dev. \\
\hline Peak water discharge $Q_{\mathrm{w}}\left(\mathrm{m}^{3} / \mathrm{s}\right)$ & 61.0 & 14.6 & 66.5 & 14.9 \\
\hline Concentration of debris-flow deposits $C_{*}$ & 0.65 & 0.03 & 0.65 & 0.03 \\
\hline $\begin{array}{l}\text { Longitudinal slope of debris-flow } \\
\text { deposits } \theta \text { (degree) }\end{array}$ & 8.0 & 0.8 & 8.0 & 0.8 \\
\hline Equilibrium debris-flow concentration $C_{\mathrm{du}}$ & 0.3 & 0.2 & 0.3 & 0.2 \\
\hline Debris-flow discharge $Q_{\mathrm{D}}\left(\mathrm{m}^{3}\right)$ & 125.9 & 35.4 & 137.3 & 37.7 \\
\hline Mean upstream debris-flow velocity $U_{\mathrm{u}}(\mathrm{m} / \mathrm{s})$ & 9.2 & 6.5 & 9.7 & 6.8 \\
\hline Debris-flow volume $V\left(\mathrm{~m}^{3}\right)$ & 39,548 & 29,198 & 43,127 & 31,644 \\
\hline
\end{tabular}

Table III. Means and standard deviations of the maximum deposition length, width and thickness for two different return periods.

\begin{tabular}{|c|c|c|c|c|}
\hline \multirow[t]{3}{*}{ Variable } & \multicolumn{4}{|c|}{ Return period $T$ (years) } \\
\hline & \multicolumn{2}{|l|}{50} & \multicolumn{2}{|l|}{100} \\
\hline & Mean & Std. dev. & Mean & Std. dev. \\
\hline Maximum deposition length $L_{\max }(\mathrm{m})$ & 97.9 & 53.9 & 107.1 & 58.9 \\
\hline Maximum deposition thickness $Z_{\max }(\mathrm{m})$ & 3.4 & 1.2 & 3.7 & 1.3 \\
\hline Maximum deposition width $B_{\max }(\mathrm{m})$ & 513.3 & 220.7 & 468.3 & 201.4 \\
\hline
\end{tabular}


and standard deviations of the maximum deposition length, width and thickness on the debris-flow fan under two conditions of return period (50 and 100 years). For the case studied herein, Table III shows that the expected maximum deposition length and thickness increase with increasing return period of rainfall intensity, whereas the expected maximum deposition width decreases with increasing return period.

The expected 3-D pictures of the debris-flow fan in different return periods are computed. Figure 4 gives the expected deposition in threedimensional form for the 50-year event. In a like manner, Figure 5 shows the result for the 100-year event. The closer the distance from the canyon mouth is, the larger the debris-flow thickness becomes.

The other objective of this paper is to compute the probability that the thickness at any point of the debris-flow fan is more than a certain height. In this paper, the certain height is taken as $3 \mathrm{~m}$ (the average height of the first floor in Taiwan). That is, one proceeds to compute the probability that the thickness at any point is more than $3 \mathrm{~m}$ using the first-order second moment method. Figures 6 and 7 represent the contours of risk, i.e. probability that thickness is more than $3 \mathrm{~m}$, for the 50 - and 100-year return period rainfall events, respectively. As shown in Figures 6 and 7,

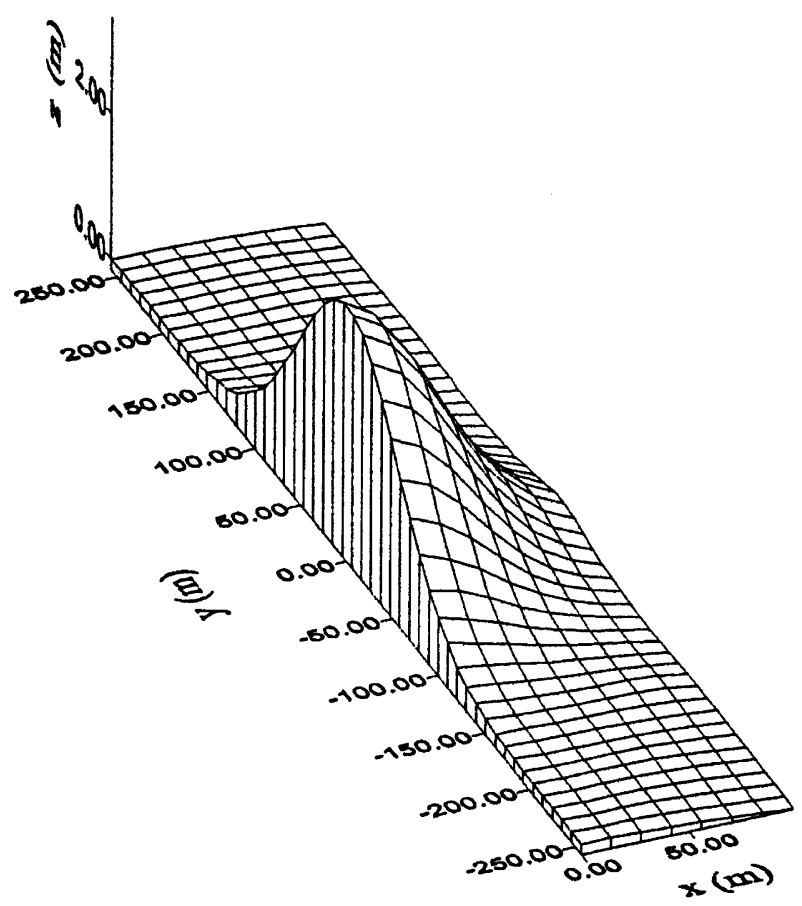

Figure 4. The expected three-dimensional form of the deposition for the 50-year event. 
one can find that the contours of probability are of the shape of an ellipse similar to the shape of deposition area. The probability that the thickness at a point is more than $3 \mathrm{~m}$ decreases as the distance of that point from the canyon mouth increases. In addition, the variation in risk decreases with increasing distance from the canyon mouth when the return period of rainfall event is fixed.

\section{Summary and Conclusions}

The primary purpose of this paper is to find the expected 3-D distribution of the debris flow and to compute the probability that the thickness at any point of the deposition area is more than a certain height. First, the configuration of debris-flow fan is described. Then, the parameters affecting the probable maximum length, width and thickness are identified and their corresponding means and standard deviations are derived. In addition, actual application of the proposed methodology is performed. As to the computation of the probability that the thickness at any point of the deposition area is more than a certain height, the first-order second moment method is used. It is found that the risk at a point decreases as the distance of that point from the canyon mouth increases. Regarding the expected deposition thickness, the closer the distance from the canyon

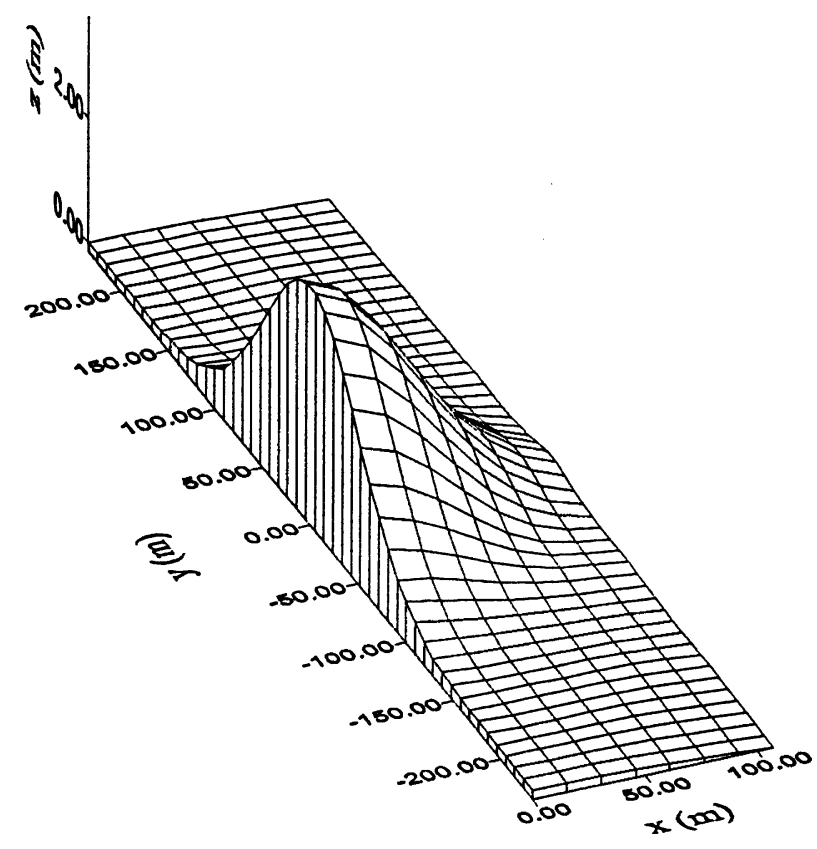

Figure 5. The expected three-dimensional form of the deposition for the 100-year event. 


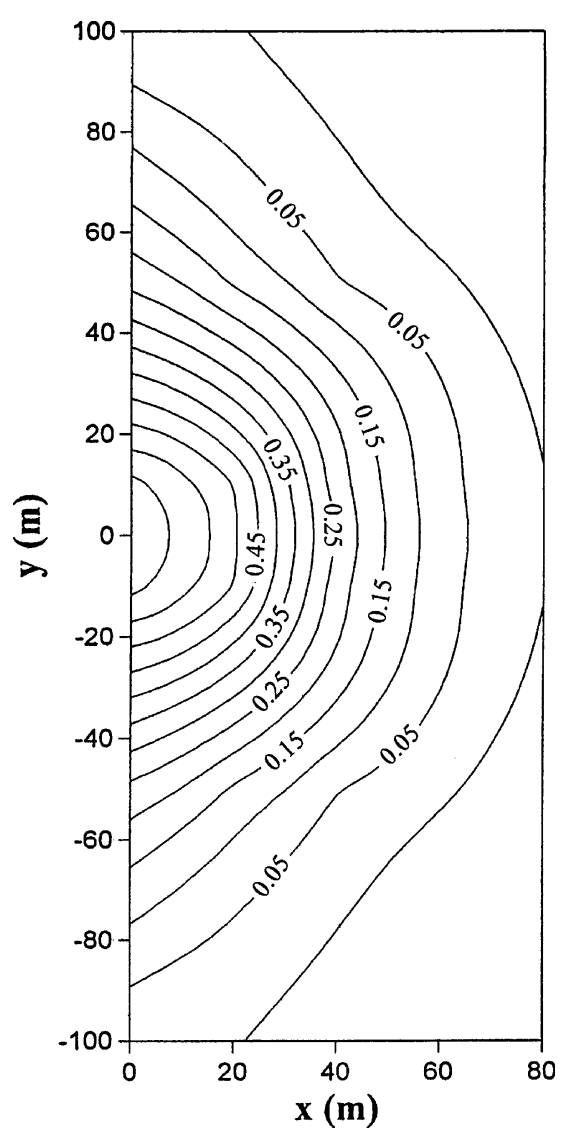

Figure 6. Contours of probability that thickness is more than $3 \mathrm{~m}$ for the 50 -year event.

mouth is, the larger the debris-flow thickness becomes. In fact, the actual topography is so complex that it will be difficult to understand the characteristics and conditions for debris flows. For the purpose of assessing risk due to debris flow events, a preliminary study was carried out in this paper (i.e. assume the geometry of the debris flow fan to be ellipsoid form). The proposed method is expected to be useful for assessment of risk due to debris flow events.

\section{Appendix A: The Maximum Deposition Length and the Maximum Deposition Width}

The probable maximum deposition length $L_{\max }$ from the end of the flow channel can be estimated from (Takahashi, 1991) 


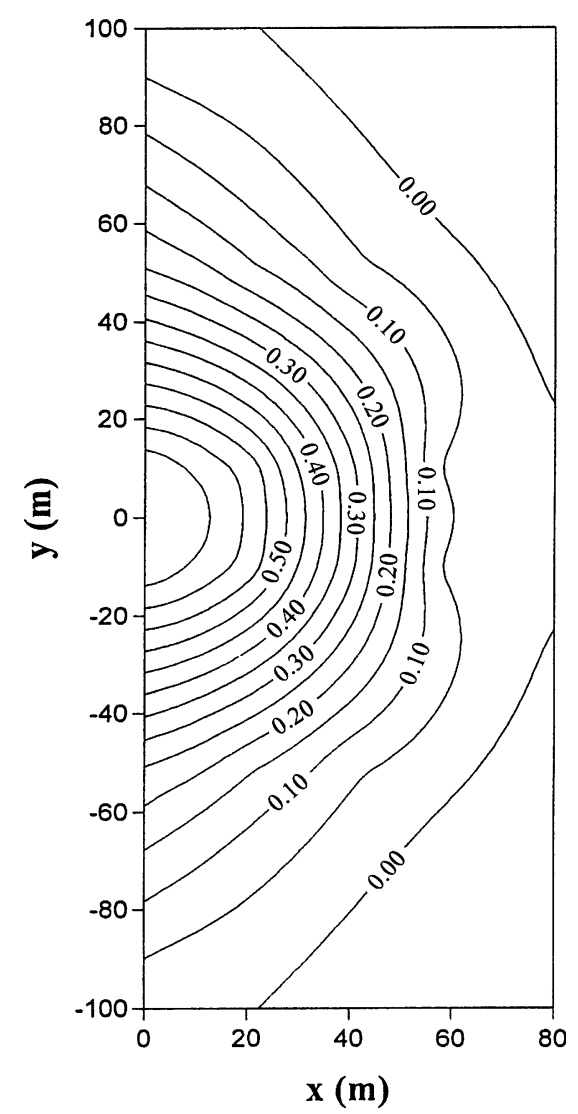

Figure 7. Contours of probability that thickness is more than $3 \mathrm{~m}$ for the 100 -year event.

$$
L_{\max }=\frac{\left\{U_{\mathrm{u}} \cdot \cos \left(\theta_{\mathrm{u}}-\theta_{\mathrm{d}}\right)\left\{1+\frac{\left[(s-\rho) \cdot C_{\mathrm{DE}} \cdot K_{\mathrm{a}}+\rho\right] \cdot \cos \theta_{\mathrm{u}}}{2\left[(s-\rho)_{\mathrm{DE}}+\rho\right]} \cdot \frac{g h_{\mathrm{u}}}{U_{\mathrm{u}}^{2}}\right\}\right\}^{2}}{\frac{(s-\rho) g \cdot C_{\mathrm{DE}} \cdot \cos \theta_{\mathrm{d}} \cdot \tan \alpha}{(s-\rho) \cdot C_{\mathrm{DE}}+\rho}-g \cdot \sin \theta_{\mathrm{d}}}
$$

where $\theta_{\mathrm{u}}$ is the bed slope of the flow channel (degree), $\theta_{\mathrm{d}}$ is the bed slope of debris-flow fan downstream of the end of the flow channel (degree), $g$ is the acceleration of gravity $\left(\mathrm{m} / \mathrm{s}^{2}\right), s$ is the density of gravel $\left(\mathrm{g} / \mathrm{cm}^{3}\right), \rho$ is the density of water $\left(\mathrm{g} / \mathrm{cm}^{3}\right), h_{\mathrm{u}}$ is the average debris-flow depth in the flow channel $(\mathrm{m}), U_{\mathrm{u}}$ is the cross-sectional mean velocity of debris flow in the flow channel $(\mathrm{m} / \mathrm{s}), K_{\mathrm{a}}$ is the coefficient of active earth pressure, $\alpha$ is the angle of dynamic friction (degree), and $C_{\mathrm{DE}}$ is the equilibrium debris-flow concentration. The values of parameters $\theta_{\mathrm{u}}, \theta_{\mathrm{d}}, s, h_{\mathrm{u}}, U_{\mathrm{u}}, \alpha$ and $C_{\mathrm{DE}}$ originate from measurement methods, field data, or the expert knowledge of the investigators. 
The probable maximum deposition width at the canyon mouth (end of the flow channel) can be estimated from (Shieh and Tsai, 1997)

$$
B_{\max }=\frac{V}{\kappa \cdot Z_{\max } \cdot L_{\max }}
$$

where $V$ is volume of debris flow $\left(\mathrm{m}^{3}\right), Z_{\max }$ is the maximum deposition thickness $(\mathrm{m})$, and $\kappa$ is a coefficient varying from 0.220 to 0.235 .

\section{Appendix B: Mean and Variance of Thickness at Any Point in the Deposition Area}

The mean value first-order second moment (MFOSM) method (Yen and Tung, 1993) is adopted to find the mean and variance of thickness at any point in the deposition area. The deposition thickness $Z_{x y}$ at any point $(x, y)$ is given by Equation (2). $Z_{\mathrm{c}}, C_{\mathrm{B}}$, and $b$ in Equation (2) are regarded as random variables. Hence, the mean $\left(\bar{Z}_{x y}\right)$ and variance $\left(s_{Z_{x y}}^{2}\right)$ of $Z_{x y}$ are

$$
\begin{aligned}
\bar{Z}_{x y} & =\bar{Z}_{\mathrm{c}} \exp \left[-\frac{1}{2 \bar{C}_{\mathrm{B}}^{2}}\left(\frac{y}{\bar{b}}\right)^{2}\right] \\
s_{Z_{x y}}^{2} & =\left\{\exp \left[-\frac{1}{2 \bar{C}_{\mathrm{B}}^{2}}\left(\frac{y}{\bar{b}}\right)^{2}\right]\right\}^{2} s_{Z_{\mathrm{c}}}^{2}+\left\{\frac{\bar{y}^{2}}{\overline{\bar{b}}^{2} \bar{C}_{\mathrm{B}}^{3}} \bar{Z}_{\mathrm{c}} \exp \left[-\frac{1}{2 \bar{C}_{\mathrm{B}}^{2}}\left(\frac{y}{\bar{b}}\right)^{2}\right]\right\}^{2} s_{C_{\mathrm{B}}}^{2} \\
& +\left\{\frac{\bar{y}^{2}}{\bar{b}^{3} \bar{C}_{\mathrm{B}}^{2}} \bar{Z}_{\mathrm{c}} \exp \left[-\frac{1}{2 \bar{C}_{\mathrm{B}}^{2}}\left(\frac{y}{\bar{b}}\right)^{2}\right]\right\}^{2} s_{b}^{2}
\end{aligned}
$$

As previously indicated, $C_{\mathrm{B}}$ ranges from 0.20 to 0.21 . It is reasonable to assume that $C_{\mathrm{B}}$ is equally likely to take any value over that range. Hence, one can refer to a general textbook of statistics to find the mean and variance of the uniformly distributed random variable $C_{\mathrm{B}}$. Moreover, $\bar{Z}_{\mathrm{c}}$ and $s_{Z c}^{2}$ are the mean and variance of the debris-flow thickness in the primary flow direction, respectively. According to Equation (1), one can obtain $\bar{Z}_{\mathrm{c}}$ and $s_{Z c}^{2}$ as

$$
\bar{Z}_{\mathrm{c}}=\bar{Z}_{\max } \exp \left[-\frac{1}{2 C_{\mathrm{L}}^{2}}\left(\frac{x}{\bar{L}_{\max }}\right)^{2}\right]
$$




$$
s_{Z_{C}}^{2}=\left\{\exp \left[-\frac{1}{2 \bar{C}_{L}^{2}}\left(\frac{x}{\bar{L}_{\max }}\right)^{2}\right]\right\}^{2} s_{Z_{\max }}^{2}+\left\{\frac{\bar{Z}_{\max } x^{2}}{\bar{C}_{L}^{2} \bar{L}_{\max }^{3}} \exp \left[-\frac{1}{2 \bar{C}_{L}^{2}}\left(\frac{x}{\bar{L}_{\max }}\right)^{2}\right]\right\}^{2} s_{L_{\max }}^{2}
$$

In Equations (A5) and (A6), the means and variances of $Z_{\max }$ and $L_{\max }$ must be computed. One can refer to Lin et al. (2004) for the mean $\left(\bar{L}_{\max }\right)$ and variance ( $s_{L_{\max }}^{2}$ ) of $L_{\max }$. According to Equation (3) in which $L_{\max }$ and $\theta$ are random variables, the mean $\left(\bar{Z}_{\max }\right)$ and variance $\left(s_{Z_{\max }}^{2}\right)$ of $Z_{\max }$ can be written as

$$
\begin{aligned}
& \bar{Z}_{\text {max }}=\bar{L}_{\max } \tan \left(\bar{\theta}-\theta_{\mathrm{d}}\right) \\
& s_{Z_{\max }}^{2}=\left[\tan \left(\theta-\theta_{\mathrm{d}}\right)\right]^{2} s_{L_{\max }}^{2}+\left[L_{\max } \sec ^{2}\left(\theta-\theta_{\mathrm{d}}\right)\right]^{2} s_{\theta}^{2}
\end{aligned}
$$

As shown in Equations (A7) and (A8), the mean and variance of $\theta$ are needed. In general, $\theta$ is between 6 and 10 degrees according to field investigation in Taiwan (Shieh and Tsai, 1997) and it is considered herein to be uniformly distributed over that range.

In Equations (A3) and (A4), terms left to be found so far are the mean $(\bar{b})$ and variance $\left(s_{b}{ }^{2}\right)$ of $b$. According to Equation (5), $\bar{b}$ and $s_{b}^{2}$ can be obtained as

$$
\begin{aligned}
& \bar{b}=\bar{B}_{\max }\left[1-\left(\frac{x}{\bar{L}_{\max }}\right)^{2}\right]^{0.5} \\
& s_{b}^{2}=\left\{\left[1-\left(\frac{x}{\bar{L}_{\max }}\right)^{2}\right]^{0.5}\right\}^{2} s_{B_{\max }}^{2}+\left\{\bar{B}_{\max }\left[1-\left(\frac{x}{\bar{L}_{\max }}\right)^{2}\right]^{0.5}\left(x^{2} \bar{L}_{\max }^{2}\right)\right\}^{2} s_{L_{\max }}^{2}
\end{aligned}
$$

As to the mean $\left(\bar{B}_{\max }\right)$ and variance $\left(s_{B_{\max }}^{2}\right)$ of $B_{\max }$ in Equations (A9) and (A10), one can refer to Lin et al. (2004).

\section{References}

Archetti, R. and Lamberti, A.: 2003, Assessment of risk due to debris flow events, Nat. Hazards Rev. 4(3), 115-125.

Bobba, A. G., Singh, V. P., and Bengtsson, L.: 1996, Application of first-order and Monte Carlo analysis in watershed water quality models, Water Resour. Manage. 10, 219-240.

Cheng, K. Y., Lin, L. K. and Chang, S. Y.: 1997, The field investigation and GIS application in a potential hazardous area of debris flow. In: Proceedings of the First International Conference on Debris-flow Hazards Mitigation: Mechanics, Prediction and Assessment, ASCE, New York, pp. 83-92. 
Cheng, J. D., Su, R. R. and Wu, H. L.: 2000, Hydrometeorological and site factors contributing to disastrous debris-flows in Taiwan. In: Proceedings of the Second International Conference on Debris-Flow, Balkema, Rotterdam, pp. 583-592.

Clague, J. J., Friele, P. A., and Hutchinson, I.: 2003, Chronology and hazards of large debris flows in the Cheekye River Basin, British Columbia, Canada, Environ. Eng. Geosci. 9(2), 99-115.

Council of Agriculture, Taiwan: 1996, The Map of Hazardous Debris-Flow Streams in Taiwan, Scale: $1 / 250,000$. (in Chinese).

Davies, T. R. H.: 1997, Using hydroscience and hydrotechnical engineering to reduce debris flow hazards. In: Proceedings of the First International Conference on Debris-flow Hazards Mitigation: Mechanics, Prediction and Assessment, ASCE, New York, pp. 787-810.

D’Ambrosio, D., Di Gregorio, S., Iovine, G., Lupiano, V., Rongo, R., and Spataro, W.: 2003, First simulations of the Sarno debris flows through cellular automata modeling, Geomorphology 54, 91-117.

Fannin, R. J. and Wise, M. P.: 2001, An empirical-statistical model for debris flow travel distance, Can. Geotech. J. 38(5), 982-994.

Hamed, M. M., Bedient, P. B., and Dawson, C. N.: 1996, Probabilistic modeling of aquifer heterogeneity using reliability methods, Adv. Water Resour. 19(5), 277-295.

Hungr, O.: 1995, A model for the runout analysis of rapid flow slides, debris flows and avalanches, Can. Geotech. J. 32(4), 610-623.

Hung, J. J.: 1996, Typhoon Herb, the New-Central-Cross-Island-Highway and slopeland failures in central Taiwan, J. Sino-Geotech. 57, 25-30(in Chinese).

Iverson, R. M.: 1997, The physics of debris flows, Rev. Geophys. 35, 245-296.

Lin, G. F. and Chen, L. H.: 2003, A reliability-based selective index for regional flood frequency analysis methods, Hydrol. Process. 17(13), 2653-2663.

Lin, P. S., Lin, J. Y., Hung, J. C., and Yang, M. D.: 2002, Assessing debris-flow hazard in a watershed in Taiwan, Eng. Geol. 66(3-4), 295-313.

Lin, G. F., Chen, L. H., and Lai, J. N.: 2004, Reliability-based delineation of debris-flow deposition areas, Nat. Hazards 32(3), 395-412.

Liu, X. and Lei, J.: 2003, A method for assessing regional debris flow risk: an application in Zhaotong of Yunnan province (SW China), Geomorphology 52(3-4), 181-191.

Major, J. J. and Pierson, T. C.: 1992, Debris flow rheology: experimental analysis of finegrained slurries, Water Resour. Res. 28(3), 841-857.

Shieh, C. L. and Tsai, Y. F.: 1997, Experimental study on the configuration of debris-flow fan. In: Proceedings of the First International Conference on Debris-flow Hazards Mitigation: Mechanics, Prediction and Assessment, ASCE, New York, pp. 133-142.

Shih, B. J., Shieh, C. L. and Chen, L. J.: 1997, The grading of risk for hazardous debris-flow zones. In: Proceedings of the First International Conference on Debris-flow Hazards Mitigation: Mechanics, Prediction and Assessment, ASCE, New York, pp. 219-228.

Sorensen, J. H.: 2000, Hazard warning systems: review of 20 years of progress, Nat. Hazards Rev. 1(2), 119-125.

Takahashi, T.: 1991, Debris Flow, A.A. Balkema Publishers, Rotterdam, Netherlands.

Wilkerson, F. D. and Schmid, G. L.: 2003, Debris flows in Glacier National Park, Montana: geomorphology and hazards, Geomorphology 55(1-4), 317-328.

Yen, B. C. and Tung, Y. K.: 1993, Some recent progress in reliability analysis for hydraulic design, In: B. C. Yen \& Y. K. Tung (eds), Reliability and Uncertainty Analysis in Hydraulic Design, New York: ASCE, pp. 35-79. 